\title{
Managing Spontaneous Bacterial Peritonitis (SBP) Patients During The Coronavirus Disease (COVID-19) Pandemic
}

\author{
Amr Ahmed Hamed, Khairy Hammam Morsy,Asmaa Naser \\ Mohammad \\ Department of Tropical Medicine and Gastroenterology, Faculty of \\ Medicine, Sohag University
}

\begin{abstract}
:
The coronavirus disease 2019 (COVID-19) is a great challenge to medical systems in affected countries. As COVID-19 came to public attention, researchers want to learn more about its spread, mortality rate, and who is most susceptible to have severe disease.

Elderly and those with other comorbidities are at the high of a severe illness. Until now, it is still uncertain of how much chronic hepatic diseases are referred to as risk factors, because of a deficiency of researches. Bacterial infections are very common in cirrhotic patients and lead to increase complications and mortality. Spontaneous bacterial peritonitis (SBP) is one of the most common complications in cirrhotic patients.

COVID-19 is not only controlling the media; but also, is making doctors worrying about its direct effect on the hepatic patient. As well, this pandemic necessitates the special arrangement of medical resources that can affect hepatic patients who continue to require medical care. So, we aimed to discuss some information and guidance for managing SBP patients during the COVID-19 pandemic.
\end{abstract}

Keywords: coronavirus (COVID-19) pandemic, spontaneous bacterial peritonitis (SBP), liver cirrhosis, The World Health Organization (WHO).

Abbreviations: COVID-19: coronavirus disease 2019, SBP: spontaneous bacterial peritonitis, SARS: severe acute respiratory syndrome, MERS: the Middle East respiratory syndrome (MERS), SARS-CoV-2: severe acute respiratory syndrome coronavirus 2, WHO: World Health Organization, ACLF: acute-on-chronic liver failure, ARDS: acute respiratory distress syndrome, ALT: alanine aminotransferase, AST: aspartate aminotransferase, MELD: model for end-stage liver disease, TIPS: transjugular intrahepatic portosystemic shunt, ULN: upper limit of normal

\section{Introduction:}

Coronaviruses are a group of viruses causing diseases as flu, severe acute respiretory syndrome (SARS), and Middle East respiratory syndrome (MERS). Last year, a novel member was recognized to be the responsible for the pandemic that began in China.
It is called severe acute respiratory syndrome coronavirus 2 (SARS-CoV-2). We now know that it causes the coronavirus disease 2019 (COVID-19). Recently, the World Health Organization (WHO) announced the COVID19 as a pandemic (1). 
Spontaneous bacterial peritonitis (SBP) is a bacterial infection of the ascites in cirrhotic patients without any intraabdominal infection or malignancy (2). We will discuss how to manage patients with SBP and COVID-19 to avoid more deterioration or progression to acute-on-chronic liver failure (ACLF), as in influenza (3).

\section{Coronavirus Disease 2019}

COVID-19 is a new illness caused by SARS-CoV-2. Last December, cases of pneumonia of unrecognized origins appeared first in Wuhan City and after that spread quickly to all China, and until now, more than 70 countries all over the world. SARS-CoV-2 patients count is growing rapidly on a universal scale (4). Simple COVID-19 cases symptoms are fever, lethargy, dry cough, and less common vomiting and diarrhea. Advanced cases suffer from respiratory distress and/or hypoxemia 7 days after the disease onset and later deteriorated to acute respiratory distress syndrome (ARDS), septic shock, acidosis, and lastly death (5)

\section{COVID-19 induced hepatic injury}

COVID-19 hepatic injury is any hepatic damage happening throughout illness development in patients with or without known hepatic diseases.

New researches on COVID-19 have detected that the frequency of liver injury fluctuated from $14.8 \%-53 \%$, mainly discovered by elevated ALT/AST levels with slight elevation of bilirubin (5). The albumin is diminished in severe cases reaching about $2.6-3 \mathrm{mg} / \mathrm{dl}$ which is linked with poor prognosis (6). The opsonic activity and complement levels are related to the ascitic protein level, so SBP is more expected in patients who have ascitic protein $<1 \mathrm{~g} / \mathrm{dL}(7)$.

\section{Spontaneous bacterial perito-nitis (SBP):}

Bacterial infections are very common in cirrhotic and are linked to increased complications and mortality (8). The commonest is SBP, around $25 \%$ of all. SBP is a bacterial infection of ascites without a source of infection (e.g. viscus perforation, abscess), inflamematory focus (as acute pancreatitis), or malignancy (2).

\section{Diagnostic difficulties:}

COVID-19 can be missed in SBP patients as it is presented with fever (5) which is common in SBP patients (9) and can be presented with diarrhea, nausea, vomiting, and abdominal pain (10) which are also signs of peritoneal irritation in SBP patients (11).

Also, COVID-19 patients may have lymphopenia (about 63\% in Wuhan, China, and $42 \%$ outside Wuhan) (12) which should be differentiated from leucopenia which is common in cirrhotic patients (9)

\section{Management of SBP patients during COVID-19 pandemic Antibiotic treatment of SBP:}

The standard regimen is intravenous cefotaxime ( $2 \mathrm{~g}$ twice daily) for five days at least (13).

Another regimen is intravenous amoxicillin/clavulanic with the same efficacy and safety as cefotaxime (14). Intravenous followed by oral ciprofloxacin also can be given (15).

Because of multi-drug resistant agents noticed primarily in nosocomial SBP, low rates of response have been developed to cefotaxime and quinolones (16). So, broad-spectrum antibiotics as carbapenems, piperacillin, and tazobactam should be started early in nosocomial SBP, especially in patients on quinolone prophylaxis (17).

General considerations (18):

-Insist on the necessity of Streptococcus pneumoniae and influenza vaccines. 
- Following strategies of secondary SBP and prophylaxis of encephalopathy to avoid more decompensation and more admission.

- Transplantation lists better to be limited to patients with priority as with ACLF, a high model for endstage liver disease (MELD) score, and HCC, not beyond Milan criteria.

- COVID-19 better to be investigated routinely before transplant in donors and recipients, putting in mind that a negative test doesn't exclude infection (18).

\section{Inpatient care (19):}

- SBP patients still need inpatient concern in the COVID-19 pandemic to prevent more decompensation and mortality as the mortality rate is about $20-30 \%$ (20).

- Relying upon the regional infrastructure, providing COVID-19-free places is necessary. As possible, SBP patients better to be hospitallized in COVID-19-free places.

- Decrease contact between medical staff and patients is important to reduce SARS-CoV-2 spread by using telem-edicine supplies (e.g., tablet).

- Decrease direct contact with highrisk patients (age $>65$ years, serious como-rbidities, immunocompromised).

- Restrict the number of relative visits inpatients.

- Ask just for crucial investigations to decrease utilizing the hospital resources.

- Consider evaluating SBP patients who develop recent encephalopathy or more decompensation for COVID-19 (19).

\section{Procedures}

- Withdraw all unurgent interventions as endoscopy or liver biopsy (21).
- Some procedures need to be done as therapeutic peritoneal aspiration, tra-nsjugular intrahepatic portosystemic shunt (TIPS), and/or upper endoscopy for gastrointestinal bleeding or follow-up band ligation in patients with new variceal bleeding. (19)

- N95 masks must be used through endoscopy (22).

\section{Treatment for COVID-19}

\section{General measures for SBP patients with COVID-19:}

- Early admission and involvement in experimental trials of COVID-19 according to guidelines. (18)

- Avoid a high dose of acetaminophen (less than 2-3 g per day if no vigorous alcohol drinking) (23)

- Avoid non-steroidal anti-inflammatory medications in cirrhotic patients with oesophageal varices (23).

- Continue treatment for complications as portal hypertension, hepatic encephalopathy. (18)

- Abnormal liver biochemistries aren't a contraindication to use investigational drugs for COVID-19 as remdesivir, tocilizumab, hydroxychloroquine and statins. But, if AST or ALT levels exceed 5 times ULN, some drugs should be avoided. (19)

- Many investigational drugs for COVID-19 could be hepatotoxic. (19)

- Close follow up of liver laboratory investigations better to be done in all patients. (19)

\section{Medical treatment:}

While now there are no medications permitted for COVID-19 treatment, numerous medications are under trial nowadays and under investigation (24). According to experience in HCV patients, decompensated cirrhotic patients better not to be managed with Lopinavir/ritonavir. Moreover, A study of 
lopinavir-ritonavir versus usual management in severe COVID-19 patients displayed no advantage (25).

Chloroquine phosphate or hydroxychloroquine is another drug under trial (26). Chloroquine has revealed antiviral activity for SARS-CoV-2 in the lab and is broadly given to severe COVID19 patients as monotherapy or with azithromycin (27).

Hydroxychloroquine isn't linked with ALT elevation and is a very infrequent cause of acute hepatic insult (18).

Decompensated patients better not to be managed with Tocilizumab. Methylprednisolone (steroids) increases the possibility of other infections in decompensated patients (18).

It is significant to remember that all these medications are still under trial and not accepted for COVID-19 treatment. But it is found that early antiviral therapy decreases the severity of the disease. It is also practical to say that early management of COVID-19 can be helpful to avoid severe pneumonia (18).

\section{Conclusion}

COVID-19 shouldn't be missed in SBP patients due to similarities in clinical presentation. SBP patients still need inpatient concern in the COVID19 pandemic to prevent more decompensation and mortality.

\section{REFERENCES}

1. Xu L, Jia Liu J, Lu M, Yang $\mathbf{D}$, Zheng $\mathbf{X}$. Liver Injury During Highly Path-ogenic Human Coronavirus Infections. Liver Int. 2020;40(5):998-1004.

2. Karvellas CJ, Abraldes JG, Arabi YM, Kumar A. Appropriate and timely antimicrobial therapy in cirrhotic patients with spontaneous bacterial peritonitis-associated septic shock: a retrospective cohort study. Aliment Pharmacol Ther. 2015; 41: 747-57
3. Schütte A, Ciesek S, Wedemeyer $H$, Lange CM. Influenza virus infection as a precipitating event of acute-onchronic liver failure. Journal of Hepatology. 2019; 70:797-99

4. Liu Y, Ning Z, Chen Y, Guo M, Liu $\mathbf{Y}$, Gali NK, et al. Aerodynamic analysis of SARS-CoV-2 in two Wuhan hospitals. Nature. 2020;582(7813):557-60.

5. Huang C, Wang $Y, L i ~ X$, et al. Clinical features of patients infected with 2019 novel coronavirus in Wuhan, China. Lancet. 2020;395(10223):497506

6. Liu W, Tao Z W, Lei W, Ming-Li Y, Kui L, Ling $Z$, et al. Analysis of factors associated with disease outcomes in hospitalized patients with 2019 novel coronavirus disease. Chin Med J (Engl). 2020;133(9):1032-38.

7. Runyon BA. Patients with deficient ascitic fluid opsonic activity are predisposed to spontaneous bacterial peritonitis. Hepatology. 1988; (3): 632-35

8. Piano S, Singh V, Caraceni $P$, Maiwall $\mathbf{R}$, Alessandria $\mathbf{C}$, Fernandez J, et al. Epidemiology and effects of bacterial infections in patients with cirrhosis worldwide. Gastroenterology. 2019; 156:1368-80

9. Dooley J, Sherlock S, Disease of the liver and biliary system 12th edition 2011,$4 ; 47,22,364-81$.

10.Wang D., Hu B., Hu C. Clinical characteristics of 138 hospitalized patients with 2019 novel coronavirusinfected pneumonia in Wuhan, China. JAMA. 2020 ;323(11):1061-69.

11.Strauss E, Caly WR. Spontaneous bacterial peritonitis: a therapeutic update. Expert Rev Anti Infect Ther. 2006; 4:249-60.

12.Fan BE, Chong VCL, Chan SSW, et al. Hematologic parameters in patients with COVID-19 infection. American journal of hematology. 2020;95.6. 13134.

13.Rimola A, Garcia-Tsao G, Navasa $\mathbf{M}$, et al. Diagnosis, treatment and prophylaxis of spontaneous bacterial peritonitis: a consensus document. J Hepatol.2000; 32:142-53. 
14. Ricart E, Soriano G, Novella M, et al. Amoxicillin-clavulanic acid versus cefotaxime in the therapy of bacterial infections in cirrhotic patients. J Hepatol. 2000;32:596-602

15.Terg R, Cobas S, Fassio E et al. Oral ciprofloxacin after a short course of intravenous ciprofloxacin in the treatment of spontaneous bacterial peritonitis: results of a multicentre, randomized study. J. Hepatol. 2000; 33: 564 .

16.Jing L, Yanhang G, Xianbo W, Zhiping Q, Jinjun $\mathrm{C}$, Yan $\mathrm{H}$ et al.. Culture-Positive Spontaneous Ascitic Infection in Patients with Acute Decompensated Cirrhosis: MultidrugResistant Pathogens and Antibiotic Strategies. Yonsei Med J. 2020;61(2):145-53.

17.Acevedo J, Fernandez J, Castro M, et al. Current efficacy of recommended empirical antibiotic therapy in patients with cirrhosis and bacterial infection. $\mathbf{J}$ Hepatol. 2009; 50(1): 5.

18.Boettler T, Newsome PN, Mondelli MU, Maticic M, Cordero E, Cornberg $M$ et al. Care of patients with liver disease during the COVID19 pandemic: EASL-ESCMID position paper, JHEP Reports. 2020; 2(3): 100113.

19.Fix OK, Hameed B, Fontana RJ et al. Clinical Best Practice Advice for Hepatology and Liver Transplant Providers During the COVID-19 Pandemic: AASLD Expert Panel Consensus Statement. Hepatology. 2020; 16;10.1002.

20.Abdel-Razik A, Mousa N, Elhammady D, Elhelaly R, Elzehery R, Elbaz $\mathbf{S}$ et al. Gut Liver. 2016; 10(4): 624-31.
21.Soetikno R, Teoh AYB, Kaltenbach T, Lau JYW, Asokkumar R, CabralProdigalidad $\mathbf{P}$, et al. Considerations in performing endoscopy during the COVID-19 pandemic. Gastrointest Endosc. 2020; S0016-5107(20):34033-5.

22.Sultan S, Lim J, Altayar O, Davitkov $P$, Feuerstein J, Siddique $S$, et al. AGA Institute rapid recommendations for gastrointestinal procedures during the COVID-19 pandemic. Gastroenterology. 2020; 31; S00165085(20)30458-3.

23. Chandok N, Watt KDS. Pain Management in the Cirrhotic Patient: The Clinical Challenge. Mayo Clinic Proceedings. 2010; 85:451-58

24.Harrison C. Coronavirus puts drug repurposing on the fast track. 2020; 38(4):379-81.

25.Cao B, Wang Y, Wen D, Liu W, Wang J, Fan G, et al. A trial of lopinavir-ritonavir in adults hospitalized with severe Covid-19. N Engl J Med. 2020; 382:1787-99.

26.Gao J, Tian Z, Yang X. Breakthrough: Chloroquine phosphate has shown apparent efficacy in the treatment of COVID-19 associated pneumonia in clinical studies. BioScience Trends. 2020; 16;14(1):72-3.

27.Gautret $\mathbf{P}$, Lagier J-C, Parola P, Hoang VT, Meddeb L, Mailhe M, et al. Hydroxychloroquine and azithromycin as a treatment of COVID19: results of an open-label nonrandomized clinical trial. International Journal of Antimicrobial Agents. 2020;105949. 